\title{
PENERAPAN TEKNOLOGI SANITASI LINGKUNGAN PADA KELOMPOK MASYARAKAT BERPENGHASILAN RENDAH DI KELURAHAN MA'RANG KABUPATEN PANGKEP
}

\author{
Faizal Amir ${ }^{*}$, Muhammad Ardi ${ }^{2}$, Bakhrani A. Rauf ${ }^{3}$, Anas Arfandi ${ }^{4}$, Hamzah \\ Nur $^{5}$, Alimuddin Sa'ban Miru ${ }^{6}$ \\ Fakultas Teknik Universitas Negeri Makassar \\ *Penulis Korespondensi: faizalamir64@unm.ac.id
}

\begin{abstract}
Abstrak
Salah satu lingkungan di Kelurahan Ma'rang Kabupaten Pangkep yang kondisi sanitasi ligkungannya tergolong buruk adalah Lingkungan Sangale. Lingkungan Sangale dihuni oleh 122 kepala keluarga (KK) yang hampir semuanya berpenghasilan rendah, yakni antara Rp. 2.000.000 sampai Rp 3.000.000 perbulan. Mata pencaharian masyarakat atau kepala keluarga di desa ini adalah: (1) buruh tani, (2) buruh tambak, (2) petani jeruk lahan sempit, (3) buruh konstruksi, (4) buruh harian pada industri semen, (5) buruh tambang, dan (6) pekerja harian yang tidak menentu. Oleh karena itu Mitra PKM ini adalah Kelompok Masyarakat yang berpenghasilan rendah yang diketuai oleh Bapak H. Ridwan. Kondisi sanitasi lingkungan permukiman, yakni sebanyak 70\% rumah tangga di Lingkungan Sangale: (1) tidak memiliki jamban keluarga yang sehat, (2) tidak memiliki tempat pembuangan sampah yang aman terhadap lingkungan, (3) tidak memiliki saluran pembuangan air kotor, (4) air bersih sangat sulit, (5) halaman rumah tidak tertata dengan baik. Kondisi tersebut diperburuk dengan rendahnya pengetahuan dan keterampilan masyarakat membuat jamban keluarga dan tempat pembuangan sampah. Selain itu juga diperparah dengan rendahnya pendapatan mereka. Tujuan PKM ini adalah sebagai berikut: (1) meningkatkan pengetahuan dan keterampilan Mitra membuat jamban keluarga yang sehat, dan (2) meningkatkan pengetahuan dan keterampilan Mitra membuat tempat pembuangan sampah yang aman terhadap lingkungan. Metode yang digunakan ada saat sosialisasi adalah diskusi dan tanya jawab. Pada saat pelatihan adalah ceramah, diskusi, tanya jawab, dan demonstrasi. Pada pelaksanaan monitoring dan evauasi adalah menyaksikan langsung kegiatan yang dilakukan oleh mitra. Hasil yang dicapai adalah: (1) Mitra memiliki pengetahuan dan keterampilan membuat jamban keluarga yang sehat, (2) Mitra memiliki pengetahuan dan keterampilan membuat tempat pembuangan sampah yang aman terhadap lingkungan, dan (3) masing-masing satu unit jamban keluarga yang sehat dan tempat pembuangan sampah yang aman terhadap lingkungan.
\end{abstract}

Kata Kunci: Jamban sehat; Lingkungan; Pembuangan sampah; Pelatihan; Sanitas.

\begin{abstract}
One of the neighborhoods in Ma'rang Sub-District, Pangkep Regency, whose environmental sanitation conditions are classified as poor is the Sangale Environment. The neighborhood of Sangale is inhabited by 122 heads of families (KK), almost all of whom have low income, which is between Rp. 2,000,000 to IDR 3,000,000 per month. The livelihoods of the community or head of the family in this village are: (1) agricultural laborers, (2) pond laborers, (2) small land citrus farmers, (3) construction workers, (4) daily laborers in the cement industry, (5) labor mines, and (6) erratic daily workers. Therefore, this PKM partner is a low-income community group chaired by Mr. H. Ridwan. The sanitary conditions of the residential environment, as many as 70\% of households in the Sangale neighborhood: (1) do not have healthy family latrines, (2) do not have landfill that are safe for the environment, (3) do not have dirty water drains, (4) ) clean water is very difficult, (5) the house yard is not well organized. This condition is exacerbated by the lack of knowledge and skills of the community in making family latrines and landfills. In addition, they are also struggled by their low income. The objectives of this PKM are as follows: (1)
\end{abstract}


increasing the Partners knowledge and skills in making healthy family latrines, and (2) increasing the Partners knowledge and skills in making environmentally safe landfills.The methods used during the socialization were discussion and question and answer. During the training there are lectures, discussions, questions and answers, and demonstrations. In the implementation of monitoring and evaluation, witnessing the activities carried out by the partners directly.The results achieved are: (1) Partners have the knowledge and skills to make healthy family latrines, (2) Partners have the knowledge and skills to make environmentally safe landfills, and (3) each unit of healthy family latrines and environmentally safe landfills.

Keywords: healthy latrines; environment; waste disposal; training; sanitation.

\section{PENDAHULUAN}

Salah satu lingkungan di Kelurahan Ma'rang Kabupaten Pangkep yang kondisi sanitasi ligkungannya tergolong buruk adalah Lingkungan Sangale. Lingkungan Sangale dihuni oleh 122 kepala keluarga (KK) yang hampir semuanya berpenghasilan rendah, yakni antara Rp. 2.000.000 sampai Rp 3.000.000 perbulan. Mata pencaharian masyarakat atau kepala keluarga di desa ini adalah: (1) buruh tani, (2) buruh tambak, (2) petani jeruk lahan sempit, (3) buruh konstruksi, (4) buruh harian pada industri semen, (5) buruh tambang, dan (6) pekerja harian yang tidak menentu. Oleh karena itu Mitra PKM ini adalah Kelompok Masyarakat yang berpenghasilan rendah yang diketuai oleh Bapak $\mathrm{H}$. Ridwan. Kondisi sanitasi lingkungan permukiman, yakni sebanyak $70 \%$ rumah tangga di Lingkungan Sangale: (1) tidak memiliki jamban keluarga yang sehat, (2) tidak memiliki tempat pembuangan sampah yang aman terhadap lingkungan, (3) tidak memiliki saluran pembuangan air kotor, (4) air bersih sangat sulit, (5) halaman rumah tidak tertata dengan baik. Kondisi tersebut diperburuk dengan rendahnya pengetahuan dan keterampilan masyarakat membuat jamban keluarga dan tempat pembuangan sampah. Selain itu juga diperparah dengan rendahnya pendapatan mereka.

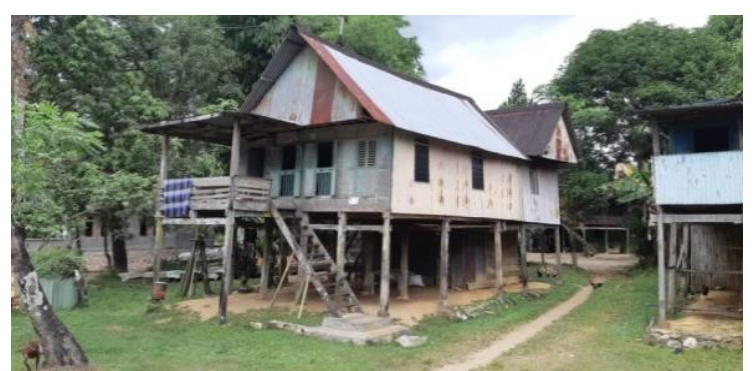

Gambar 1. Rumah yang tidak memiliki jamban keluarga dan tempat sampah.

Tujuan PKM ini adalah sebagai berikut: (1) meningkatkan pengetahuan dan keterampilan Mitra membuat jamban keluarga yang sehat, dan (2) meningkatkan pengetahuan dan keterampilan Mitra membuat tempat pembuangan sampah yang aman terhadap lingkungan.

Teori yang mendasari PKM ini diuraikan sebagai berikut. Penelitian Bakhani (2017) dan (2018) tentang Perilaku Masyarakat Ekonomi Lemah Menyediakan Jamban Sehat di Wilayah Pesisir dan Dataran Rendah, menunjukkan bahwa perilaku masyarakat tersebut menyediakan jamban sehat sangat rendah. Notoatmodjo (2007) menyatakan bahwa bangunan jamban keluarga harus memenuhi persyaratan kesehatan, yakni bersih, dan cuku air untuk digunakan. Salvato (1982), menyatakan bahwa syarat jamban keluarga harus menggunakan ventilasi agar supaya ada sirkulasi udara dan septic tank harus menggunakan penutup dan lubang udara dari pipa sehingga bau dapat diminimalisir. Chandra (2007), menyatakan bahwa jamban keluarga adalah suatu bangunan yang digunakan untuk membuang dan mengumpulkan kotoran manusia yang disebut WC sehingga aman terhadap lingkungan permukiman.

Sampah yang disebut juga sebagai limbah padat (solid waste) menurut Tchobanoglous, et al. (1993) adalah semua benda yang berasal dari kegiatan manusia maupun hewan yang tidak diinginkan atau yang dibuang untuk dimusnahkan. Adibroto, Wahyono dan Bebassari (2004) mengemukakan bahwa sampah merupakan salah satu produk samping dari kegiatan manusia seiring dengan semakin berkembangnya perekonomian suatu perkotaan, yang berpengaruh pada jumlah sampah yang dihasilkan seiring dengan pertambahan jumlah penduduk dan ragam kegiatannya. Azwar (2012) menjelaskan bahwa sampah adalah bagian dari sesuatu, sisi-sisa bahan yang tidak dipakai, tidak disenangi atau sesuatu yang harus dibuang, karena tidak memiliki nilai ekonomi. Agar sampah tidak mencemari lingkungan, maka sampah tersebut perlu 
di buang pada tempat pembuangan sampah sementara (TPS) yang selanjutnya dibuang ke tempat pembuangan akhir sampah (TPA).

\section{METODE}

Untuk memulai kegiatan PKM, terlebih dahulu ketua pelaksana kegiatan memohon izin kepala Pemerintah Kelurahan Ma'rang untuk memperoleh izin lokasi. Selanjutnya dilakukan persiapan lokasi. Persiapan lokasi berfokus pada Lingkungan Sangale, yakni pada Kelompok masyarakat berpendapatan rendah. Metode yang digunakan adalah diskusi dan tanya jawab.

Sosialisasi dilakukan pada Lingkungan Sangale yang berfokus pada kelompok masyarakat berpendapatan rendah. Materi sosialisasi adalah: (1) tujuan dan manfaat jamban keluarga dan tempat pembuangan sampah, (2) bahan dan alat yang digunakan, dan (3) cara pembuatan jamban keluarga dan tempat pembuangan sampah. Metode yang digunakan adalah disukusi dan tanya jawab dengan pihak mitra.

Pelatihan dan pendampingan terhadap Mitra berfokus pada acara membuat:

1. Konstruksi jamban keluarga yang sehat yang dimulai dari: (a) menggali tanah untuk lubang penampungan tinja atau septic tank, (b memasang dinding septic tank dengan pasangan batu merah, (c) memplester dinding septic tank, (d) membuat penutup septic tank dengan konstruksi beton, (e) membuat konstruksi perembesan, (f) membuat lantai WC dan memasang closet, dan (g) memasang pipa pembuangan tinja dari closet ke septic tank. Metode yang diguakan: demonstrasi, diskusi, dan tanya jawab.

2. Konstruksi tempat pembuangan sampah yang aman terhadap lingkungan, mulai dari:

(a) pemasangan pondasi dari batu gunung,

(b) pemasangan lantai konstruksi beton,

(c) pemasangan dinding pasangan batu merah, dan

(d) memplester pasangan dinding dan lantai. Metode yang digunakan: demonstrasi, diskusi, dan tanya jawab.

Monitoring dan evaluasi dilakukan pada saat pelaksanaan kegiatan PKM sedang berlangsung. Metode yang digunakan adalah memihat langsung mitra membuat konstruksi jamban keluarga yang sehat dan konstruksi tempat pembuangan sampah yang aman terhadap lingkungan.

\section{HASIL DAN PEMBAHASAN}

Pelaksanaan dan hasil kegiatan PKM ini diuraikan sebagai berikut:

1. Memberikan Penyuluhan

Materi kegiatan penyuluhan yang diberikan mitra adalah: (a) jamban keluarga yang sehat, dan (b) tempat pembuangan sampah yang aman terhadap lingkungan. Hasil yang dicapai setelah penyuluhan adalah mitra dan seluruh anggotanya memiliki pengetahuan: (a) jamban keluarga yang sehat, (b) tempat pembuangan sampah yang aman terhadap lingkungan, (c) dampak negatif tinja dan sampah yang dibuang sembarang tempat.

\section{Melatih dan Mendampingi Mitra}

Kegiatan pelatihan dan pendampingan membuat jamban keluarga yang sehat yang dimensi konstruksi bak penampungan tinja (septictank) adalah: panjang $=1,5$ meter, lebar $=1,10$ meter, kedalaman $=2$ meter. Kegiatan yang dilakukan dalam melatih dan mendampingi mitra untuk membuat konstruksi bak penampungan tinja (WC) atau septictank yang di mulai dari: (1) menggali lubang bak penampungan tinja (septictank) sesuai ukuran yang sudah ditentukan (2) membuat campuran pasangan untuk memasang dinding batu merah, (3) membuat campuran plasteran untuk memplaster dinding batu merah, (4) memasang pipa perembesan sesuai ukuran yang telah ditentukan, (5) membuat bekesting penup konstruksi, (6) memotong dan memasang besi penutup konstruksi sesuai ukuran dan jumlah yang telah ditentukan, dan (7) melakukan pengecoran. Hasil yang dicapai adalah satu unit septictank lengkap dengan konstruksi perembesan.

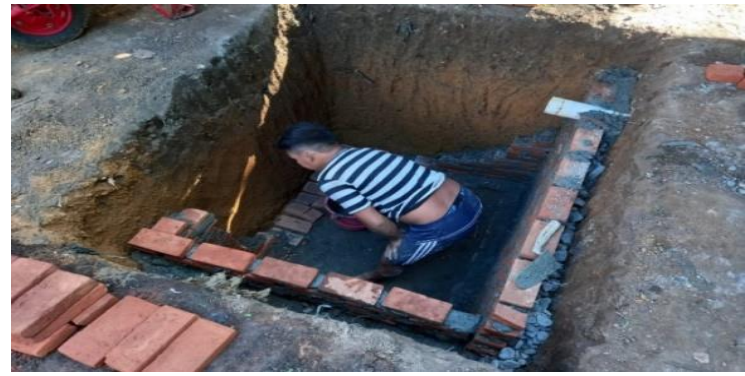

Gambar 2. Memasang batu merah sebagai dinding septictank 


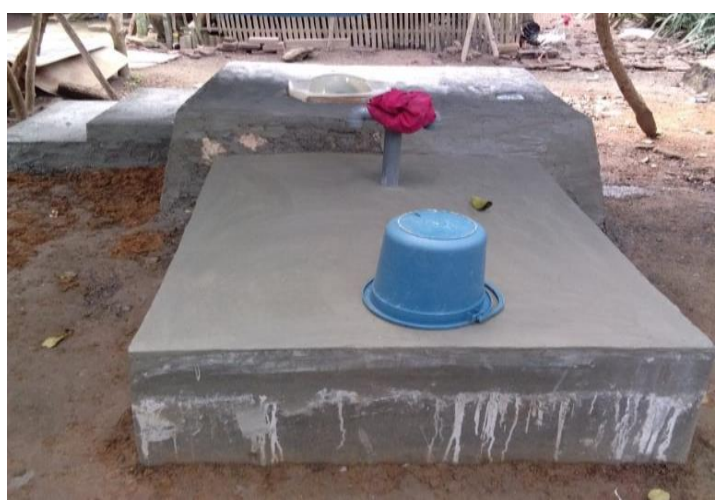

Gambar 3. Hasil PKM berupa jamban keluarga yang sehat dan aman terhadap lingkungan yang dilengkapi konstruksi perembesan.

Kegiatan pelatihan dan pendampingan membuat konstruksi perembesan dimuali dari: (a) menggali lubang perembesan sesuai kedalaman yang sudah ditentukan, (b) menyusun batu gunung, menghampar pasir, dan kerikil sesuai ukuran yang sudah ditentukan, (c) memasang pipa rembesan yang sudah dilobang-lobangi dan sudah dibalut ijuk sesuai ukuran yang sudah ditentukan, (d) menutup plastik pipa rembesan agar tidak dimasuki pasir dan dan tanah, (e) memasang atau menyusun batu gunung yang ukurannya kecil di atas pipa rembesan, menghampar pasir dan kerikil sesuai ukuran yang sudah ditentukan, dan(f) menutup lubang perembesan dengan tanah campur pasir sampai serata permukaan tanah asli disekitarnya. Dimensi konstruksi perembesan adalah: panjang: 1,2 meter, lebar $=1$ meter, kedalaman $=1,2$ meter.

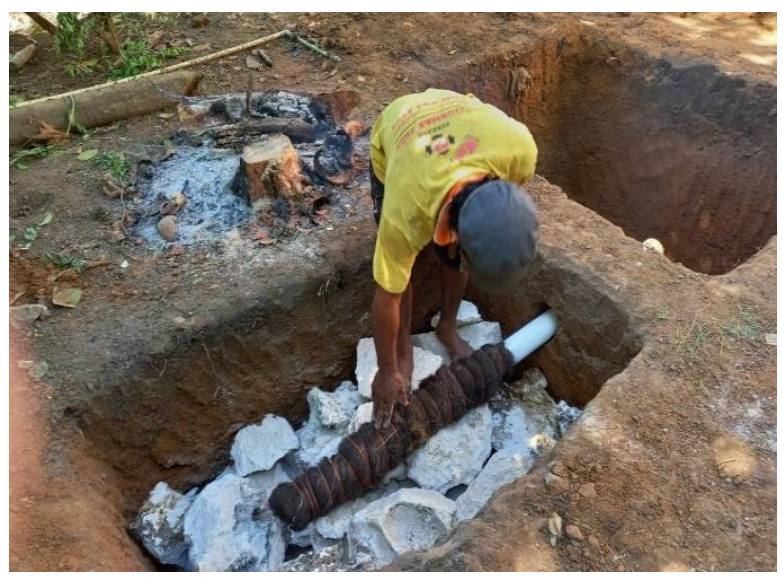

Gambar 4. Proses pemasangan pipa paralon yang menghubungkan septic tank dengan perembesan
Kegiatan pelatihan dan pendampingan membuat tempat pembuangan sampah yang aman terhadap lingkungan, dimulai dari: (a) menggali tanah sesuai ukuran, (b) memasang pondasi dan tiang sesuai ukuran, (c) membuat bekesting lantai, (d) memasang besi dan melakukan pengecoran, dan (e) memasang dinding batu merah dan melakukan plasteran sampai selesai. Konstruksi pondasi adalah pasangan batu gunung dengan tebal $30 \mathrm{~cm}$. Konstruksi lantai adalah pasangan batu merahdengan tebal $20 \mathrm{~cm}$. Konstruksi dinding adalah pasangan batu merah dengan ukuran: lebar $=70 \mathrm{~cm}$; panjang $=70$ $\mathrm{cm}$; dan tinggi $=70 \mathrm{~cm}(70 \times 70 \times 70 \mathrm{~cm})$. Hasil yang dicapai adalah satu unit tempat pembuangan sampah yang aman terhadap lingkungan.

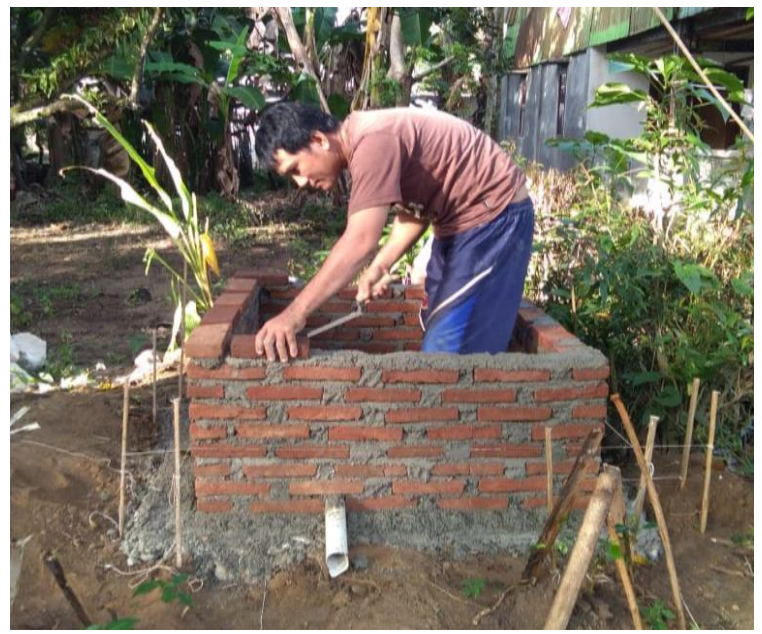

Gambar 5. Proses pemasangan batu merah sebagai dinding tempat sampah

\section{KESIMPULAN}

Kesimpulan kegiatan PKM ini adalah sebagai berikut:

1. Mitra memiliki pengetahuan tentang bahan dan alat yang digunakan untuk membuat jamban keluarga yang sehat dan tempat pembuangan sampah yang aman terhadap lingkungan.

2. Mitra memiliki pengetahuan tentang cara membuat jamban keluarga yang sehat dan tempat pembuangan sampah yang aman terhadap lingkungan.

3. Mitra memiliki keterampilan membuat jamban keluarga yang sehat dan tempat pembuangan sampah yang aman terhadap lingkungan. 


\section{UCAPAN TERIMA KASIH}

Ucapan terima kasih disampaikan masing-masing kepada:

1. Mensristek/BRIN dan Dirjen Dikti atas pendanaan kegiatan PPPUD sebagi bentuk pembinaan dosen di Perguruan Tinggi

2. Rektor Universitas Negeri Makassar atas izin, pembinaannya, dan motivasinya sehingga kegiatan Tri Dharma Pergurun Tinggi ini terlaksana dengan baik.

3. Ketua Lembaga Penelitian dan Pengabdian kepada Masyarakat (LP2M) Universitas Negeri Makassar atas dukungan dan arahannya melakukan kegiatan PPPUD ini dengan baik.

4. Pemereintah Kabupaten Wajo atas dukungandan pemberian izin untuk melakukan keggiatan PPPUD.

5. Mitra PPPUD atas partisipasi dan kerja samanya.

6. Seluruh anggota tim pelaksana kegiatan PPPUD atas kerja samanya yang baik.

7. Seluruh pihak yang telah berpartisipasi dalam kegiatan PPPUD ini yang tidak sempat disebutkan satu persatu.

Semoga apa yang telah dilakukan oleh semua pihak dalam mensukseskan kegiatan PPPUD ini dapat memberi manfaat yang sebesar-besarnya bagi Masyarakat, Bangsa dan Negara. 